\title{
JURISPRUDENCE
}

\author{
Battakhov P.P. \\ Candidate of Law Sciences, senior research associate of the sector of enterprise and corporate \\ law of Institute of state and law of the Russian Academy of Sciences (IGP RAS)
}

\section{MAIN PROVISIONS OF SOCIAL ENTERPRISE IN RUSSIA}

\begin{abstract}
This article discusses the concept of the social orientation of activity and the entrepreneurial approach at the level of the Russian Federation, including a number of aspects of the legal regulation of public relations between organizations of state power and social entrepreneurs. The main problem of the study is the study of the sequence of the assignment of the status of a social enterprise by the authorities Russia at the federal level. Currently, the question is being raised about the adoption of a separate federal legislative act "On the development of small and medium-sized enterprises in the Russian Federation." The introduction of the relevant law is necessary, since the reasons are the basis for the inevitability of consideration of public problems and the adoption of relevant official documents in all regions of the Russian Federation.
\end{abstract}

Keywords: business, investment, social project, bill, state, economic entity, social enterprise

Entrepreneurship in the Russian Federation exists in a difficult situation. Since 2014, the state has been under sanctions from European countries and the United States. In the economy, public-industrial corporations and budget-forming companies suffered the most damage. The most difficult task to resolve is considered the gradual disappearance of small businesses from the market. As a result, the State has set up specific measures to support enterprises, after which the Federal Law of 24.07.2007 No. 209-FZ has been amended [1]. The current law describes the main features of Russian social entrepreneurship, for this reason the possibility of improving a new direction without the assistance of the state is excluded.

Today, social entrepreneurship is considered one of the most important and in demand areas. Public policy allows the formation of social entrepreneurship at the federal level. At the moment, entrepreneurial relations are regulated sufficiently by public authorities at all levels. To this end, mandatory laws are adopted at each level of government to improve the regulation of social entrepreneurship.

Today, businessmen developing an economic entity in the social sphere are improving more and more seriously at the federal level. The state authorities discuss many aspects of the state's impact on social relations of social entrepreneurship, and various scientific conferences and forums raise current problems. Current activities are supported by the head of state. Currently, amendments have been made to the Federal Law "On the Development of Small and Medium-Sized Enterprises in the Russian Federation." This law expresses all the features of the settlement of the considered category of entrepreneurial activity.

The state needs a separate federal bill regulating social entrepreneurship. At the moment, the territorial units of Russia need to adopt their own laws governing the legal relations of participants. Such actions in the future will ensure significant progress in the development of the economic sphere of the state, their implementation will require the support of state authorities. Unfortunately, the social institutions of our state act without giving the expected result. For this reason, in the Russian Federation, as in foreign countries, social enterprises created on the partnership of the state and a private entrepreneur began to arise. 
The development of such enterprises has a positive impact on the resolution of public problems in the state. In addition, this process elevates the economy of the state to parity. An economic figure acquires financial assistance, and the state, in turn, guarantees the implementation of this social program throughout the period under consideration. In the future, such projects will certainly affect the growth of the country's economy, resolving socially significant problems at the federal level.

On the basis of Art. 2 of the Civil Code of the Russian Federation "Relations regulated by civil law," entrepreneurship involves the constant profit from economic activity. While social entrepreneurship can be characterized in an additional direction affecting the execution of the social part. As a result, the central operating person of social entrepreneurship carries out activities related to the production and manufacture of goods for profit and the implementation of the social part of this project. As a result, the above-mentioned relations, which are related to entrepreneurship in the social sphere, must be regulated by certain norms of civil and entrepreneurial law.

The basic law of the Russian Federation provides the opportunity to apply entrepreneurial abilities and owned things for the process, the purpose of which is to make a profit[2]. Regulation of the relations of business participants has a positive effect not only on the state, but also on society as a whole, allowing to ensure the public rights of citizens.

This type of entrepreneurship should also be understood as the individual desire of the entrepreneur for self-organization, caused by the need to solve specific social issues. It is customary for a social entrepreneur to designate a person who has decided to take up a certain social task, using his own experience in entrepreneurship. Entrepreneurial principles are necessary for a person to create civic capital oriented not only towards earning earnings. The main task of this type of entrepreneurship is participation in solving social and economic issues, which in the future will certainly have a favorable effect on the level of consumption of citizens and the economy of the state.

Such people are in most cases organizations that do not have profit-making as the main purpose of activity. At the same time, it is important to understand that obtaining a positive difference between total incomes is an important component of the social enterprise system. It should be taken into account that social entrepreneurship is a term that has appeared relatively recently. In particular, in Russia, the definition was first publicly enshrined only in 2008. In addition, today there is no one generally accepted term in the world that defines social entrepreneurship.

The main trend for businessmen is to solve a particular social problem. More recently, a social project was considered at various sites in Russia. The organizations of state power of the Russian Federation and the owners of economic entities realized the inevitability of changes after including certain amendments to specific articles of the Federal Law "On the Development of Small and Medium-Sized Enterprises in the Russian Federation" in 2019. After that moment, Federal Law No. 245-FZ, which included the terms[3] "social entrepreneurship" and "social enterprise" in the code of laws of the Russian Federation, was fixed at the official level.

For production entities, this trend is relatively new. In the Russian Federation, entrepreneurs have long been engaged in solving public issues independently, without the participation of state assistance, probably, and are currently working on similar projects. Now economic entities are implementing this activity with the support of the state. It follows that modern entrepreneurship is a profitable partnership for both parties: production entities and state power. As a rule, projects receive funding from the state and economic entities at a time.

The main features of this project are profit-making and solving problems of well-being of citizens. St. 3 p. 8 of the Federal Law sets out the term of a social enterprise as follows: an entrepreneurial entity that carries out activities in the field of social entrepreneurship[4]. Along with this requirement, the person establishing laws as acts of state power establishes a restriction on the categories of activities of economic entities. 
Social changes in society in and the solution of significant social problems are the problems of the modern direction. Speaking about the difference between charity work, it should be understood that social entrepreneurship in all cases has a commercial nature of activity. We denote the most detailed explanation of social entrepreneurship. Social entrepreneurship should be understood as an entity that is aware of certain social challenges that need to be addressed through entrepreneurial activity.

In the current economy, judgment is especially popular, in which one of the main differences of social entrepreneurship is considered its advanced nature. This assumption allows the possibility that entrepreneurship in such circumstances should be modified, in other words, a fresh look at the implementation of social services is necessary .

Modified in modern terms, a business entity that implements continuous activity in entrepreneurship and works on ways of developing modern society, in order to increase the standard of living of certain groups of the population and generate profits for the future improvement of the organization, is considered a social enterprise.

Today, in order to acquire the status of a social enterprise, a businessman needs to pass the state-accepted selection. For the first time, enrollment in the written list took place on April 1, 2020. For this reason, social entrepreneurs received new restrictions. Currently, the status of a social entrepreneur is confirmed annually, but it is extremely difficult to do without entering the register. The process provides a large quantity of opportunities to develop social projects.

Thus, State bodies provide assistance by providing information and financial resources. In order to obtain the relevant status, a person wishing to engage in social entrepreneurship must overcome two stages of registration. Under these conditions, the process is carried out on the basis of the law "On state registration of legal persons and individual entrepreneurs." Only after passing this procedure can a citizen apply for the status of social entrepreneur .

Nevertheless, at the moment, the process of obtaining the status of a social entrepreneur is usually difficult. In addition to the above processes, the entity engaged in independent entrepreneurial activity must determine the scope of activities of a social enterprise. The list of permissible variations in the performance of social entrepreneurship according to Art. 24.1 Federal Law of the Russian Federation has restrictions. This official document raises a large number of questions. Projects are often supported in the Russian Federation but do not provide effective results. Unfortunately, in the modern world, the majority of persons receive cash or inkind assistance provided by the state, without implementing numerous promising areas. For the success of such a project, the Federal Executive is obliged to exercise control to avoid problems in the future. On the basis of paragraph 1 of Art. 24.1 of the Civil Code of the Russian Federation, the most successful and justified condition in the code of laws is the fact that the economic entity must provide labor employment to entities counting on obtaining a place in a social organization. These include individuals with disabilities in physical or psychological development, large families, persons without formal registration, graduates of social institutions for orphans and children left without parental care, single citizens, poor citizens, refugees, pensioners.

The list of categories of citizens should be supplemented by introducing the indigenous small peoples of Russia in order to obtain a position in these enterprises. For a more detailed explanation of the topic, we refer to the term "social enterprise." In the laws of the Russian Federation, this definition is formulated as an independent economic entity in the field of small and medium-sized enterprises. The least studied issue at present is considered the obligation of the parties in the process of executing the activities of a social enterprise. Entities that carry out production in Russia, have not fulfilled or have fulfilled, but not fully obligations, will be fully responsible for this.

As an exception, there are cases in which the fulfillment of tasks and deadlines was prevented by circumstances that could not be foreseen or prevented, for example, natural disasters (paragraph 3 of article 401 of the Civil Code of the Russian Federation). In addition to other laws, paragraph 401 of the Civil Code of the Russian Federation is recognized as the 
exclusive basis for establishing responsibility in social entrepreneurship. The process of changing this area provides for amendments to the legislation of the Russian Federation that can fully disclose the essence of the new direction.

As an example, a proposal is considered to add an appendix to paragraph 1 of Art. 401 of the Civil Code of the Russian Federation, determining that the responsibility of the enterprise should be assigned only for certain guilt. In other words, social enterprises that have been registered on a special list are obliged to receive mitigation of measures of influence, due to the fact that their initiative is aimed at achieving goals in the social sphere [6]. There is another concept according to which profits are distributed among each business entity. In accordance with the legislation of Russia, the share of profits of a joint-stock company or other business entity in a commercial organization is divided between legal or physical persons that created the organization, while in non-profit organizations such a phenomenon is excluded. A similar trend exists in social entrepreneurship.

This type of entrepreneurship contributes to improving the welfare of the population of the state. Thus, the main social issues and the creation of conditions for the formation of civil society are being resolved. A successful example of this activity is the construction of social infrastructure, in particular educational institutions, medical institutions, boarding schools, which compensates for the existence of imperfections in public life. Based on this, the correct decision will be to include in Federal Law No. 209-FZ a modern definition of a social enterprise. In the newest version, the term acts as a legal person that has been registered in proper status, as well as performing social tasks to achieve the well-being of citizens.

Also, paragraph 4 of this Federal Law emphasizes that social entrepreneurship cannot be understood as certain commercial activities for the production or sale of products with an indirect tax imposed at the time of production on goods of mass consumption within the country[5].

Social entrepreneurs are new people in situation, aimed at achieving positive results with the help of advanced opportunities, providing social support and solving the social problems of citizens. Such enterprises exist both in the commercial and non-commercial form of the organization, also based on public-private partnership. The principles of the functioning of social entrepreneurship are social innovation, profit-making and solving social problems for a certain category of society.

There are several specific problems in this area. First, the lack of awareness among the general public of the theory and practice of social entrepreneurship .In addition, the practice of social entrepreneurship is not widespread at the massive level in the regions. Neither social entrepreneurs themselves perceive themselves as such, nor other subjects of public relations realize them as such [6].

In Russia, social entrepreneurship does not cover all areas, many niches are clogged by other economic entities, therefore it is difficult to compete with giants, but over time, if the state begins to provide proper support, economic entities will identify economic barriers and further develop other areas. In some areas, entrepreneurs will not be able to develop at a high level without state support. For the first three years, the state should support such entrepreneurs not only financially, but also in a consultative manner. Authorized bodies are obliged to take measures to support entrepreneurship. This may be, for example, accelerated registration of social organizations in the field. If we take another aspect of relations, it is worth saying that entrepreneurs must fulfill all the promised obligations to the state. The goal for them should be not only to arrive, but also to fulfill a social mission. In modern Russia, unfortunately, in this field and on theory, and in practice, there are many problems that need to be completely solved in the near future.

Social entrepreneur the main goal sees the creation of an effective business model aimed at solving or mitigating public inconsistencies. The organization of a socio-entrepreneurial project made it possible to increase the level of the economy of Russia, since the quality of life of citizens is directly proportional to the international authority of the entire state. The direction 
of development of this sphere is observed on the basis of a study of the activities of the Government of the Russian Federation aimed at creating acts of supreme legal force. Thus, in 2020, the legal status of a social enterprise became official thanks to the accepted conditions for passing the registration procedure at the Ministry of Economic Development of the Russian Federation. At the moment, a number of problems remain that need to be eliminated for the subsequent formation of social entrepreneurship in Russia. Currently, there is no whole definition of this term. Experts in the economic sphere explain it in different ways. Based on the Civil Code of the Russian Federation, entrepreneurship is recognized as an independent activity, the main purpose of which is to generate profit [2]. In addition, the law emphasizes that it is carried out at its own risk.

Due to the fact that modern laws require the introduction of new standards in the field of social entrepreneurship, the practice of their application does not yet allow us to analyze the effectiveness. Therefore, a number of significant problems are currently encountered in social entrepreneurship[3]. Some proposals should be made to improve the performance of social entrepreneurs. In order to improve the organization of social entrepreneurship, the following are necessary:

*Agree on a separate bill on social entrepreneurship;

*Adopt social entrepreneurs as independent entities at the legislative level;

*Simplify the process of receiving support from government agencies at the federal level;

* Social entrepreneurs should be liable in accordance with paragraph 1 of Art. 401 GKRF only for guilt;

* Introduce preferential lending for entrepreneurs[3];

* Exempt entrepreneurs from income tax for three years;

* Obtaining subsidies for business development;

*Social facilities should be temporarily donated for the development of social programmes.

In many subjects of Russia, the introduced law does not work. Over the past five years, entrepreneurial activity has gradually disappeared. To do this, the state must support this social project for the breakthrough development of the country's economy. It is also necessary to invest in social entrepreneurship on a parity basis. In Russia, at the moment it is impossible to solve the described tasks without attracting economic entities. Therefore, the time has come in tandem to develop the joint project on favorable terms and implement it.

Thus, the necessary support from the authorized bodies in all government structures will lead to the development of social entrepreneurship and will give a big impetus to a new direction that will work for the future of the Russian economy. To do this, the state must not interfere with entrepreneurs with complicated procedures, but, on the contrary, reduce the barrier for novice social entrepreneurs.

\section{References}

1. Law of July 24, 2007 N 209-FZ "On the Development of Small and Medium-Sized entrepreneurship in the Russian Federation "//Parliamentary newspaper of August 9, 2007 N99101.

2. Shcherbachev E.D. Development of housing construction in post-rebuild Russia//Economics in industry. M.2011. Page 38-43.

3. Battakhov P.P. The concept and features of social entrepreneurship//Modern Science. 2020. № 2-2. Page 113-119.

4. Sergeev A.P. Intellectual Property Law in the Russian Federation. M.: Prospect, 2006.

5. Katyukhova P.B., Petrukhin E.M. Assurance of tax maneuver for independent oil refiners: path to modernization or real threat to small business//Problems of economy and management of oil and gas complex. 2019. № 5(173). Page 5-12.

6. Savelyev A.V. Prospects of Social Entrepreneurship//In the collection: Modern management: development vectors. Collection of scientific works of international scientific and practical conferences. 2018. Page 309-310. 